\title{
Influence of pitting corrosion on fatigue and corrosion fatigue of ship structures Part I
} Pitting corrosion of ship structures

Marek Jakubowski, Assoc. Prof. Gdansk University of Technology

\begin{abstract}
The present paper is a literature survey focused on a specific kind of corrosion, i.e. pitting corrosion and its influence on fatigue of ship and offshore steels. Mechanisms of a shortand long-term pitting corrosion in marine environment have been described including pit nucleation and growth phases. Some models of pit growth versus time of exposure have been presented. Some factors which influence the pit growth rate have been discussed briefly.
\end{abstract}

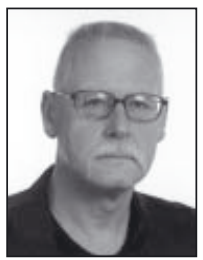

Key words: pitting corrosion; ship structures; offshore structures

\section{INTRODUCTION}

There are two groups of actions which can lead to damages of real structures:

- chemical or electrochemical, if undesirable, are identified with corrosion $(\mathbf{C})$

- mechanical, usually identified with stresses or strains (S).

Damages resulting from interaction of both stresses and corrosion are usually considered as an aspect of one of them: influence of stress on corrosive damage, or influence of corrosion on mechanical damage. In this author's opinion interaction of corrosive and mechanical factors is the most general case. Almost all corroding structures are stressed. Almost all stressed structures are operated in an environment not neutral for mechanical damage process. In fact any damage (D) can be considered as: $\mathrm{D}=(\mathrm{C}+\mathrm{S})_{\mathrm{D}}$.

Pure mechanical or pure corrosive damage can be considered to be specific and unusual cases. In the case of vacuum or inert gas environment $\mathbf{C}=0$ can be assumed and damage is purely mechanical in nature, while for very low stress levels $\mathbf{S}=0$ can be assumed and damage is purely corrosive.

The above given statement is especially true for ship structures which are the main object of the present research. Corrosive environment of the structures in question is also the main source of service loads.

There are many kinds of corrosion but for ship hull structures which work in sea environment, electrochemical corrosion is important. Both general (almost uniform) and local (pitting) corrosion is observed in low and medium strength steels and their welded joints in sea environment. The uniform corrosion is not ideally uniform, i.e. the thickness reduction is not uniform over the whole corroding surface, and pits are not classic in shape - their depths are often much smaller than diameters (low aspect ratios).

Metal surface always exhibits some differences in potential of different areas. Corrosion results in corrosion cells. Anodes and cathodes in such cells are in short circuits with negligible ohmic resistance. At the areas of lower potentials, i.e. anodes, metal ions come off the metal surface to the corrosive electrolyte (seawater) and they leave free electrons on the metal surface. This process is called anodic dissolution. The electrons flow to the adjoining cathodic areas where they are taken off the metal surface by so called depolarizers D (atoms, molecules or ions) that are reduced.

Faraday's law and polarization curves evaluated in shortduration laboratory tests were used for calculation of corrosion rates and life of corroding structures. Such approach is correct for a relatively short life of structure. It is well known, however, that corrosion products are deposited over the metal surface, e.g. red-brown rust is produced in low-carbon lowalloy steels.

Presence of rust layer of increasing thickness on the surface of structure changes the kinetics of corrosive reactions leading to a decrease of the corrosion rate with the rusting progress thus also with time. Many authors have considered limitation of the main depolarizer, i.e. oxygen supplied to cathodic areas by diffusion through the rust. A simplified formula is usually proposed for the corrosion loss $y$ in function of the exposure time t [29]:

$$
\mathrm{y}=\mathrm{At} \mathrm{t}^{\mathrm{B}}
$$

where A and B are empirical constants. Although B should be equal to 0.5 for Fickian diffusion and homogeneous rust layer, calibration to field data shows values between 0.3 and 0.8 [29]. 


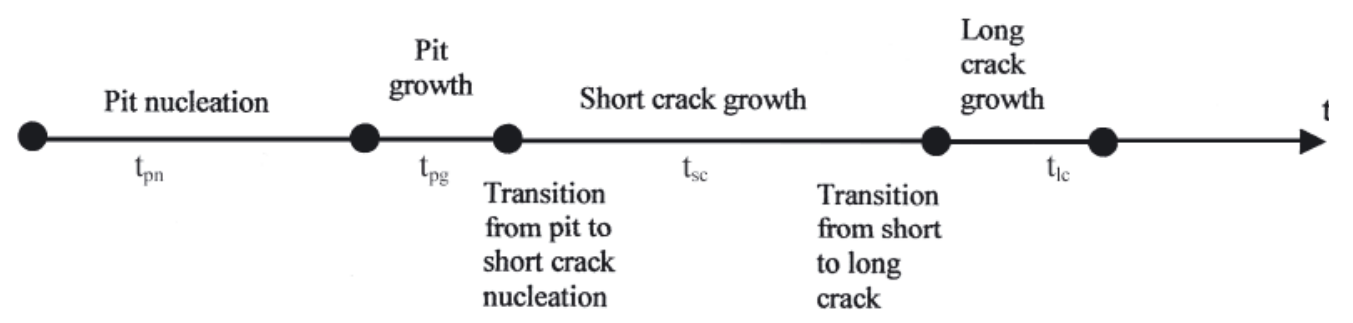

Fig. 1. Seven stages of pitting corrosion fatigue life [4]

Predictions of very long-term corrosion wastages based on the above given equation (1) lead to significant deviations from field data and do not explain a large scatter band of the data.

Melchers [29] stated that the corrosion process is more complex than that approximated by simple empirical models and a single formula of type (1a). In his numerous publications (not referred to here) he elaborated a new multi-phase model.

In common opinion, pits, if they are present on the material surface, are almost always the potential sites of the fatigue cracks initiation. Pits formation period is a part of total fatigue and corrosion fatigue life of structures exposed to marine environment during manufacturing or service stage. Every model of pitting corrosion fatigue process which could be applied to in-service life prediction, contains pit growth, pit-to crack transition and fatigue crack growth. Most complete seems to be the assumption, originally proposed by T. K. Goswani and D. W. Hoeppner and accepted by Shi and Mahadevan [3, 4] that the pitting corrosion fatigue process proceeds in seven stages shown in Fig. 1.

Total pitting corrosion fatigue life of a structure where damaging crack is initiated at pit, can be calculated as the sum of the duration times of the following four phases:

$$
\mathrm{t}_{\mathrm{f}}=\mathrm{t}_{\mathrm{pn}}+\mathrm{t}_{\mathrm{pg}}+\mathrm{t}_{\mathrm{sc}}+\mathrm{t}_{\mathrm{lc}}
$$

where:

$\mathrm{t}_{\mathrm{pn}}$ - the time for pit nucleation,

$t_{\mathrm{pg}}$ - the time for pit growth,

$t_{\mathrm{sc}}$ - the time for short crack growth,

$t_{l c}-$ the time for long crack growth.

The present paper describes the phenomena and modelling of first two stages of the process, i.e. pit nucleation (initiation) and pit growth (propagation).

\section{MECHANISM OF PITTING CORROSION}

\subsection{Pit nucleation (initiation)}

In marine environment pitting occurs when the anodic area are fixed at the structure surface.

Butler [5] tested pure iron and its alloys. On pure iron the grain boundary region rather than the grain boundary itself is preferred site of initial attack of pitting corrosion. It suggests that even high-purity iron may have some metallurgical or chemical heterogeneity. Some pits can be initiated near inclusions. The greater tendency for pitting to originate at such sites may be associated with stresses in the crystal lattice surrounding the inclusions. In this author's opinion, however, it could be caused by electrochemical potentials of inclusion and iron.

In technical metals and alloys, corrosion pits almost always initiate at some chemical or physical heterogeneity on the metal surface, such as inclusions, second phase particles, flaws, mechanical damage, or dislocation [6]. In steels, however, pitting corrosion is almost always initiated at sulphide inclusion - this is commonly accepted opinion since the beginning of $20^{\text {th }}$ century [7]. As a rule, sulphides contain about $90 \% \mathrm{MnS}$, remaining sulphides in mild and low alloy steels are mainly FeS.

Sulphides have usually cathodic potential, while the surrounding matrix is anodic [42]. There are different theories, but it is generally agreed that the sulphide inclusions or the immediate area surrounding the inclusions (contaminated by sulphur) are anodic with respect to the steel matrix, and that the hydrogen sulphide $\mathrm{H}_{2} \mathrm{~S}$ and HS- ions enhance the local corrosion [7, 8, and 9]. The hydrogen sulphide and HS- catalyse the anodic dissolution of iron and poison the cathodic reaction of hydrogen depolarisation $[7,8,9]$. The dissolved $\mathrm{Fe}^{2+}$ and $\mathrm{Fe}^{3+}$ ions are hydrolysed. These reactions cause local acidification of the electrolyte and enhance (catalyze) further dissolution of the steel and dissolution of sulphide inclusion producing $\mathrm{H}_{2} \mathrm{~S}$ and $\mathrm{HS}^{-}$and originating micro pits. Both $\mathrm{MnS}$ and $\mathrm{FeS}$ inclusions exhibit sufficient solubility even in neutral water. Local attacks first occur in only a few places at the interface between the inclusion and matrix. Next macro pits are generated as a result of formation, growth and coalescence of micro pits at the mentioned interface [9]. Less soluble FeS are much more detrimental due to: (i) higher solubility in the steel matrix, and (ii) higher electric conductivity.

A micro-pit of only a few microns is formed very quickly after immersion and this time is a true initiation time [8]. The moment when the initiation stage transforms to propagation is not distinct. Sometimes corrosive attack starts from existing voids between the sulphide and the matrix [7, 9]. In standard nonalloy steels having small content of active sulphides, most of pits reach the depth of $100 \div 200 \mu \mathrm{m}$ and then stop to propagate [7, 8]. Such pits are called micro-pits. They can continue their growth only under a layer of dirt or corrosion products. In classical approach, the early development of mini-pitting is entirely attributed to dissolution of sulphide inclusions. If proportion of active sulphides in the steel is high enough, the dissolution of active iron around the sulphide inclusion may expose a new underlying active sulphide, the attack around the latter exposes still another active sulphide, and so on. In this way a macroscopic pit is generated [7].

All engineering alloys are covered with passive films of some oxides [10] which - in some cases - can facilitate local corrosion initiation in local sites of the film breakdown by an active anion (usually $\mathrm{Cl}$-). Further growth of micro-pit is driven by difference of potentials between cathodic film and anodic alloy. This is often the case for high-alloy $\mathrm{Cr}$ or $\mathrm{Cr}$-Ni stainless steels. In non-alloy structural steels the oxide film exhibits very weak passive properties and does not effectively protect the steels against general uniform corrosion which takes place all over the steel surface, not only at the film local breakdown sites.

Role of paint coating for the pitting nucleation can be interpreted analogously to the role of passive films. Until the classification rules were amended in 1992, the coating of hold frames was not required and the frames were not coated [11]. Then, only general corrosion of the frames was observed. Now, when the hold frames have protective coatings such as tar epoxy paints, pitting corrosion is observed [11]. It means 
that the coating which protects steel structures against general corrosion, facilitates the pitting corrosion process. The pits are presumably created at some inherent defects of coating or in-service - produced damages like scratches etc.

\subsection{Pit growth (propagation)}

When a pit has reached a certain depth, it has passed the initiation (or nucleation) stage and the propagation (or growth) stage begins. The propagation stage usually is much longer than the initiation period. However, if this pit nucleation period is neglected in the predictions of the total life of the structure, the final results are slightly more conservative [12].

An oxygen concentration cell is now formed with a small anode within the pit and a large cathode on surrounding steel surface. The metal ions produced by anodic dissolution are hydrolyzed, that leads to acidification of electrolyte in pits. Novokshchenov [13] has reviewed many literature data showing more or less marked potential and $\mathrm{pH}$ drop within pits compared to the external conditions. Butler et al. [5] reported relatively shallow pits (of the depth below $50 \mu \mathrm{m}$ ) in pure iron and the potential fallen by about $100 \mathrm{mV}$ at the pit centre, while $\mathrm{pH}$ dropped from a value about 8 well away from the pit to a value of about 2 at its centre. The acidity was not confined to the pit but extended over a region of about 15 - pit diameter. Thus the processes realized within the pit create favourable conditions for the pit growth, and the growth is autocatalytic.

The pit growth mechanism with the main electrochemical reactions is shown in Fig. 2. The scheme first proposed by Wranglen (Fig. 2a) [7] has been adapted and simplified by Novokshchenov [13] for steel in concrete, and the Novokshchenov's scheme has been again adapted for steel in marine environment with some modifications and simplifications introduced by Biezma and Rio-Cologne (Fig. 2b) [14]. The Wranglen's scheme gives the most complete picture of the pit propagation.

From the bottom and side walls of the pit, iron is dissolved anodically as $\mathrm{Fe}^{2+}$ ions which migrate and diffuse outwards, whereas anions, e.g. chloride ions, migrate into the pit. On their way outwards $\mathrm{Fe}^{2+}$ ions are partly hydrolyzed with the acidification of the inside-pit electrolyte. In low-alloy steels, by further reactions, they create precipitations of black magnetite and red-brown rust, often forming a crust (blister, dome) above the pit. Hydrogen ions discharged at the sides of the pit, partly form adsorbed atoms $\mathrm{H}_{\text {ads }}$ and next they are absorbed, and partly form $\mathrm{H}_{2}$ gas that causes occasional bursting of the blister.
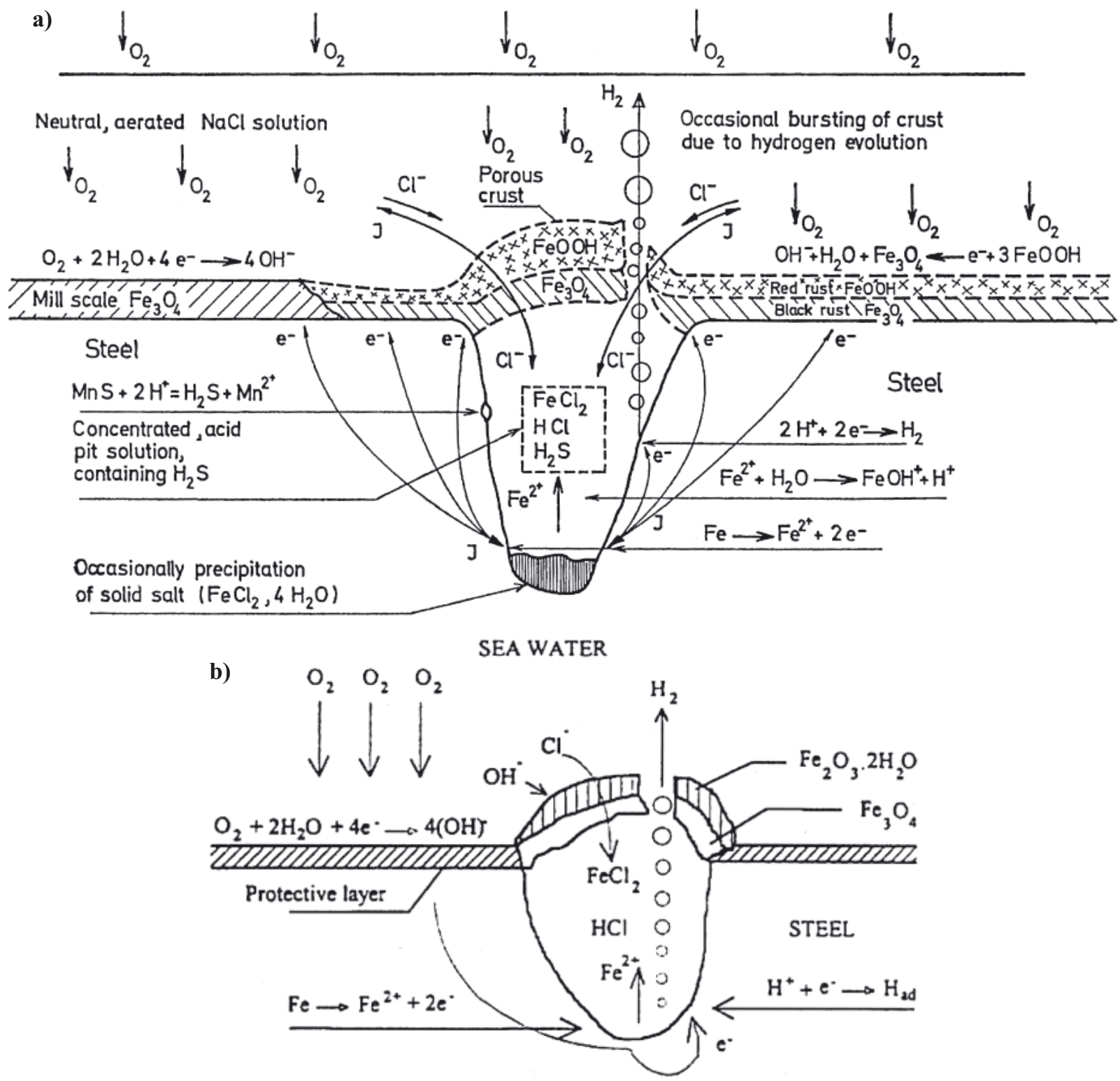

Fig. 2. Growth of steel corrosion pits to be in near - neutral chloride solutions (a) [7]; (b) [14] 
The autocatalytic conditions created by a pit are the following [7]:

1) within the pit:

- preventing passivation:

a) small supply of oxygen;

b) generation of an acidic pit solution by hydrolysis reaction;

c) dissolution of sulphides, resulting in $\mathrm{H}_{2} \mathrm{~S}$;

d) enrichment of anions $\left(\mathrm{Cl}^{-}, \mathrm{SO}^{2-}\right)$ attracted by cathions in the pit;

e) high electric conductivity of high-concentrated pit solution;

2) in the pit mouth:

- formation of the crust, counter-acting mixing of the pit and bulk solutions, thus maintaining the oxygen concentration cell;

3) around the pit:

- reducing general corrosion:

a) partial cathodic protection by the corrosion current;

b) passivation due to cathodically formed alkali, particularly in hard water.

The above described mechanism suggests that pits should grow still deeper and deeper. The author's own observations and literature information show that real macro pits on surfaces of steel ship structures are rather very broad and not very deep, e.g. $50 \mathrm{~mm}$ broad, $2 \div 3 \mathrm{~mm}$ deep, all over their surfaces, i.e. with approximately flat, but irregular bottom. It can be deduced that at least some of pits begin to grow into diameter direction and, in consequence, coalescence with adjacent pits occurs. Also, investigations of pure iron showed that some pits grow by coalescence. The reason why their growth in depth direction slows down is not clear for this author, but its possible explanation is - as shown in Fig. $2 \mathrm{a}$ - that occasionally solid salts can be deposited over the bottom of the pit.

Propagation of pit depth conventionally is described by power-law model [8] analogous to that for general corrosion rate:

$$
a_{p}=A \cdot\left(t-t_{i}\right)^{B}
$$

In practice the time for the pit nucleation $\left(t_{i}\right)$ is negligible compared to the pit propagation time hence the pit growth is usually described by:

$$
\mathrm{a}_{\mathrm{p}}=\mathrm{A} \cdot(\mathrm{t})^{\mathrm{B}}
$$

Exemplary constants are as follows:

- $\mathrm{A}=0.092$ and $\mathrm{B}=0.511$ for a carbon steel immersed in salt water [15], and

- $A=0.0028$ and $B=0.3877$ for a typical mild steel used for ship structures sprinkled with sea water twice a day over 20 days period [16].

Exponent $B=0.3 \div 0.5$ has been evaluated for aluminium alloys and solid stainless steels (i.e. the materials covered with a stable oxide films) in salt water [17]. Eq. (1c) is relevant for micro-pits rather than for macro-pits, and for exposure periods usually much shorter than 1 year and usually measured only in hours or days [8]. Wang et al [18] tried to apply the model (1c) to describe eight-year test results of macro pits (up to $2.4 \mathrm{~mm}$ deep) in different steels. They obtained relatively satisfactory values of coefficient of determination $\mathrm{R}^{2}=0.915 \div 0.98$, but in this case for shorter exposure periods (1 year) and $\mathrm{a}_{\mathrm{p}}<0.4 \div 0.6 \mathrm{~mm}$ the pit depth was markedly overestimated while for a longer exposure the pit depth was a little underestimated (up to about 10\%).

\section{INFLUENCE OF BIOLOGICAL ACTIVITY OF MARINE ENVIRONMENT}

\subsection{Introduction}

Kobzaruk et al [19] exposed some specimens of mild steel in natural sea water (of $1.8 \%$ salinity) in situ and in the very same natural sea water in laboratory tanks. Marked differences were found in results. Many deep and sharp corrosion pits were observed in specimens tested in situ, while sporadic, shallow and non-sharp pits were revealed in specimens tested in laboratory. The difference was attributed to the biological activity of water in situ with marine growth on the specimen surfaces and lack of such activity of the same water stored in laboratory. Therefore the metal surfaces submerged in sea were non-uniform from electrochemical point of view and some bacteria could influence the pits growth too. Authors did not consider that, but the conditions around and within the pits were rather aerobic since the exposition time was 5500 hours, while Melchers [20] considered that aerobic conditions are likely to exist up to about $1 \div 1.5$ years of in situ exposition. Thus aerobic bacteria played presumably the main role in the case of investigations [19].

Sulphate-reducing bacteria (SRB) play a very important role in pitting corrosion in anaerobic conditions that presumably dominate within pits and in their neighbourhood after longer periods of the steel surface exposition to seawater in situ, e.g. longer than $1.5 \div 2$ years of exposition. At the bottom of cargo tanks on tankers and of fuel tanks such conditions can occur even earlier.

There is always an at least thin layer of water under fuel and oil in tanks. Marine SRB proliferate in the anaerobic conditions often existing in seawater underlying fuels [21]. Sulphur and sulphur compounds are produced by the metabolic reduction of sulphate by anaerobic bacteria. Different kinds of bacteria have been found in water on the bottom of the tanks. The association of the different species of micro - organisms causes, through a symbiotic action, favourable conditions for the growth of anaerobic bacteria. Steel in seawater contaminated by SRB is characterized by a change of pitting and corrosion potential to more active (more negative) potentials. The breakdown of passivity is accomplished easily in deaerated solutions where low levels of sulphide or metabolic products are needed. Therefore at the bottom plates of cargo holds of many tankers some extremely deep hemispherical pits of order of $10 \mathrm{~mm}$ or more in depth can be sometimes found.

\subsection{Melchers model}

Real pit depths in ship structures, especially after a longterm exposition to marine environment, do not agree with predictions by the conventional power-law equations (1c). In Melchers' opinion [9] the reason is that after long period of exposure, conditions on the corroding surface change from an essentially aerobic to an essentially anaerobic environment, thereby creating conditions that allow a much greater rate of corrosion through the metabolism of SRB. Melchers [9] elaborated a multi-phase model of pit depth growth including this observation. The model is shown in Fig. 3.

In the phases $0,1,2$ the corrosion rate is controlled mainly by oxygen supply rate to the bottom of the pit, and the pit depth growth can be described approximately by the relation (1c), at least for the phases 0 and 1 . At the end of the phase 2, corrosion rate is sufficiently declined mainly due to build-up of corrosion products reducing the rate of oxygen transport to the corroding surface (mainly the pit bottom), and - to a lesser 


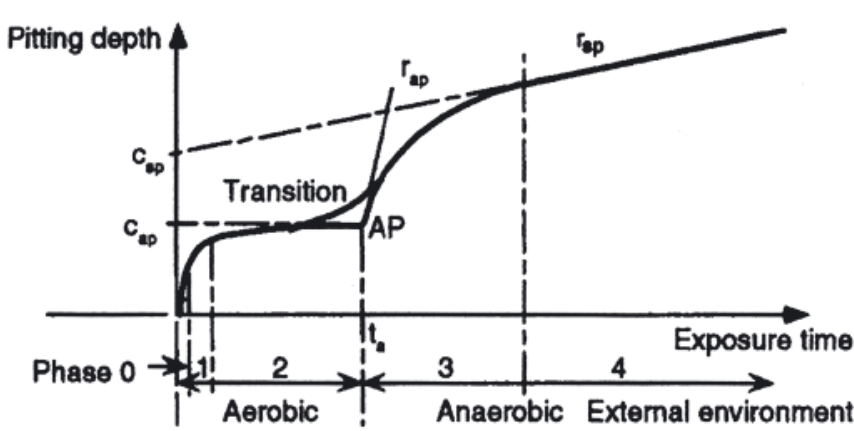

Fig. 3. Melchers' pitting corrosion model including the SRB activity [9]

extent - the effect of fouling. The life $\left(\mathrm{t}_{\mathrm{a}}\right)$ of the phases $1 \div 3$ strongly depends on the seawater temperature $(\mathrm{T})$ and is given by $[8]$ :

$$
t_{a}=9.91 \exp (-0.088 \mathrm{~T})
$$

For cold North Sea water this is 4-years period while for warm waters of temperature $20^{\circ} \mathrm{C}$ or more this is less than 1 year. This is also idealized beginning of the anaerobic phase 3. Total maximum pit depth at this moment $\left(\mathrm{c}_{\mathrm{ap}}-\right.$ see Fig. 3$)$ is given by an equation of the analogous form [8]:

$$
\mathrm{c}_{\text {ap }}=9.91 \exp (-0.052 \mathrm{~T})
$$

Thus, at the moment of commencement of the anaerobic phase 3, for warm water the pit depths are still in the range of micro-pits $(200 \mu \mathrm{m})$ while for cold water they are evidently of macro-pits $(800 \mu \mathrm{m})$. The pit depth in these equations means its absolute value, i.e. the depth "as measured" (relative value) plus the equivalent, one - sided, general corrosion loss.

Although some SRB activity is likely to occur soon after immersion, it tends to be suppressed in the early stage of the corrosion process. Renewal of the SRB activity is observed at the end of the phase 2, when the corrosion products layer is thick and regular and creates appropriate anaerobic conditions for the entire metal surface. Therefore similar trends are observed for pitting corrosion (Fig. 3) and general corrosion described in [9]. It means that there is an interaction between pitting and general corrosion loss [9].

To sustain the corrosion process in the phase 3 and 4 in particular, nutrient must be transported through the corrosion products. It is likely that the rate of this supply will control the rate of corrosion in the mentioned phases. The SRB-induced corrosion produces new products which reduce the rate of supply of nutrients, leading to reduction of corrosion rate in the phase 3 and eventually to near-steady corrosion process in the last phase 4 .

The above statements concerned pitting which proceeds in external anaerobic conditions in the late phases of a structure work. Conditions within pits, however, are locally favourable for SRB activity even in aerobic external environment because of lower $\mathrm{pH}$, lower oxygen concentration, some $\mathrm{H}_{2} \mathrm{~S}, \mathrm{FeCl}_{3}$ and $\mathrm{HCl}$ content [9]. Near the edges of the pit the aerobic bacteria which can exist in the external environment, will become dormant or die because of local oxygen deficiency. This provides a source of nutrient additional to nutrient from the external environment. The nutrients transported to the pit interior, provide conductive conditions for the rapid growth and metabolism of SRB. Thus even (i) under generally external aerobic conditions (ii) without the presence of further sulphide inclusions around the pitted area, further pit growth could occur due to local generation of $\mathrm{H}_{2} \mathrm{~S}$.

Melchers proposed the following explanations for widening of pits and coalescence of them during the phase 3:

- availability and rate of supply of nutrients to SRB,
- their rate of metabolism as governed by energy supply rate and temperature and concomitant rate of production of hydrogen sulphide $\mathrm{H}_{2} \mathrm{~S}$,

- the interaction with other bacteria and with marine growth,

the morphology of the pits,

- usual presence of partially protective deposits at the bottom of the pits (Fig. 2a).

Melchers [8] has evaluated some exponential equations which enable to calculate the pitting rate at the commencement of the phase $3\left(\mathrm{r}_{\mathrm{ap}}\right)$ and the constants $\left(\mathrm{c}_{\mathrm{sp}}\right.$ and $\mathrm{r}_{\mathrm{sp}}-$ meanings of the constants are explained in Fig. 3). He concludes that the rate of pit growth eventually steadies, in the last anaerobic phase, to a rate about the same as that for general corrosion. Thus, the size of pit measured from the actual material surface will practically not increase during this phase.

\subsection{Wang et al. model [18]}

Wang et al. [18] did not consider complex multiphase physical-chemical-biological mechanism of pitting corrosion but they proposed a simple engineering model. They adopted a Weibull function to describe the growth of macro-pits in function of exposure time:

$$
\mathrm{a}_{\mathrm{p}}=\mathrm{d}(\mathrm{t})=\mathrm{d}_{\mathrm{m}}\left\{1-\exp \left[-\left[\alpha \cdot\left(\mathrm{t}-\mathrm{T}_{\mathrm{i}}\right)\right]^{\mathrm{m}}\right]\right\}
$$

the corresponding pit growth rate is given by:

$$
a_{\mathrm{p}}{ }^{\prime}=\mathrm{d}^{\prime}(\mathrm{t})=
$$

$$
=\mathrm{d}_{\mathrm{m}} \cdot \mathrm{m} \alpha^{\mathrm{m}}\left(\mathrm{t}-\mathrm{T}_{\mathrm{i})}{ }^{\mathrm{m}-1} \exp \left[-\left[\alpha \cdot\left(\mathrm{t}-\mathrm{T}_{\mathrm{i}}\right)\right]^{\mathrm{m}}\right]\right.
$$

where: $d_{m}$ means the long-term depth of pits; $m$ is the shape parameter; $\alpha$ is the scale parameter. For $m>1$ the pit growth rates exhibit an increasing phase, next the maximum and a decreasing phase (Fig. 4a), while for $\mathrm{m} \leq 1$ the pitting corrosion rates drop monotonically.

The new model is only applicable to the growth phase of macro-pits. Exemplary conformance of the model with the data on the maximum depths of pits, published by Melchers, is shown in Fig. 4b. The data points for micro-pits cannot be well described by this simple model because of the high non-linear phenomena in the considered phase of pitting. The authors [18] ascertained that for assessment of time-dependent reliability of ship structures it is essential to inspect the weakening of structural load - carrying capacity in the long term. Therefore, the influence of micro-pits may be neglected in the meaning of engineering practice. This statement seems to be controversial in the light of many investigations (discussed below) which showed marked influence of micro-pits on fatigue and corrosion fatigue life of specimens made of different materials.

Wang et al [18] evaluated influence of environmental variables and the steel composition on the parameters $d_{m}, m$ and $\alpha$. Contrary to Melchers [8] who considered all steels (even medium-carbon ones) as one population independently on the chemical composition, Wang and co-workers stated a marked influence of carbon, sulphur and manganese content in steel on the model parameters $\mathrm{d}_{\mathrm{m}}, \mathrm{m}$ and $\alpha$.

\subsection{Conical pits}

Most of published papers are focused on pits of a hemispherical (or a spherical sector) shape (Fig. 5a) [22]. Investigations of actual corroded hold frames of bulk carriers which carry exclusively coal or iron ore, revealed that corrosion pits are often of a conical shape (Fig. 5b) [23]. The pits are 

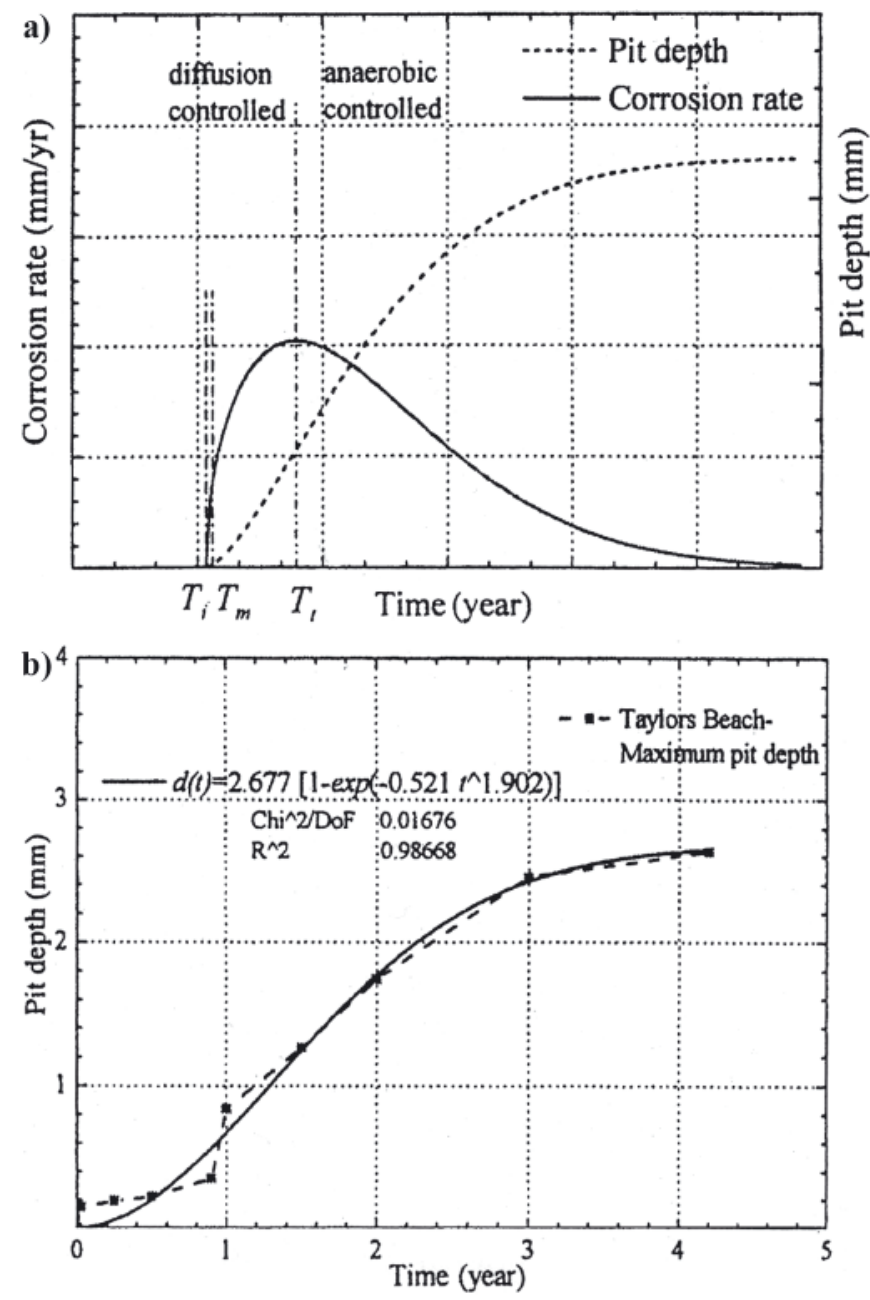

Fig. 4. Wang et al model [18]: (a) schematic plot of basic relations, (b) the model fitting to all maximum pit depth data from a research at Taylor's Beach, Australia

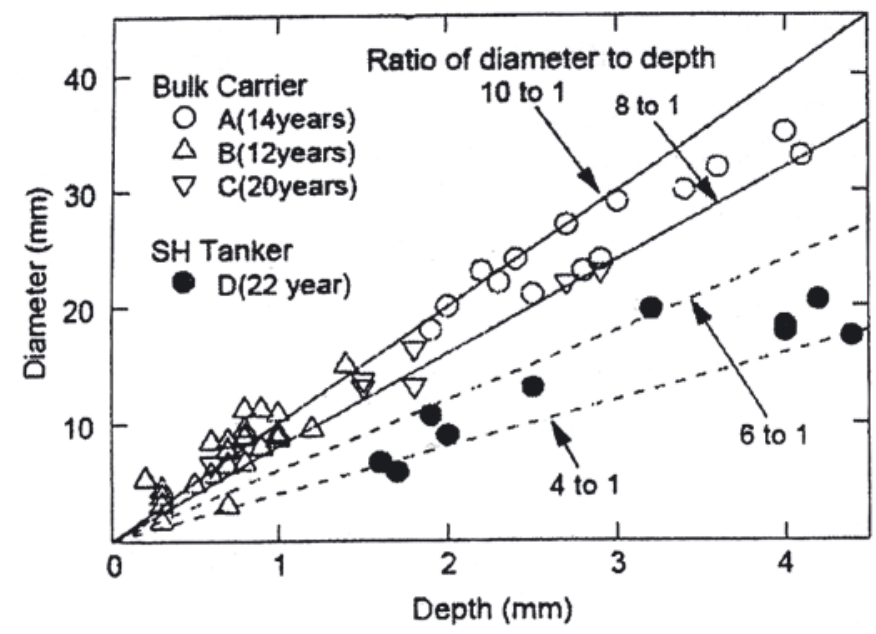

a)
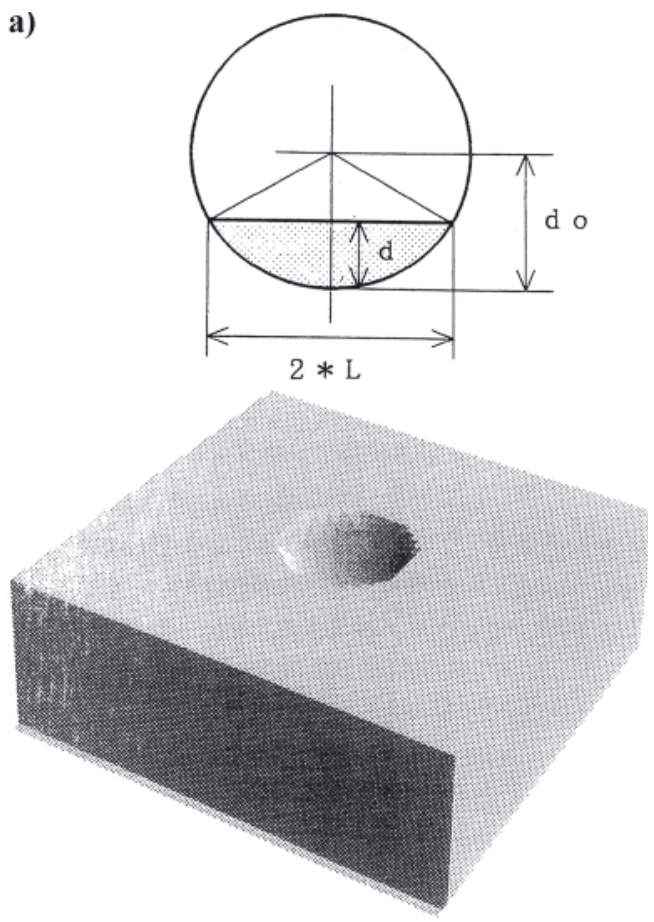

b)

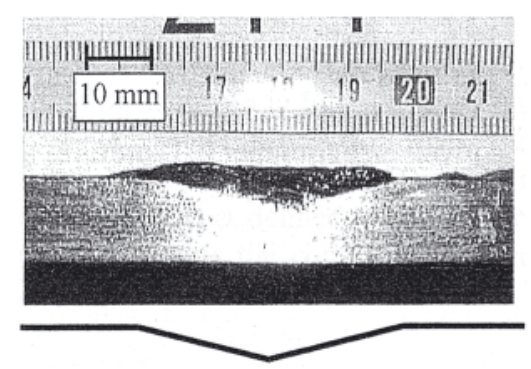

Fig. 5. Pits: (a) view of a spherical one (typical for e.g. tankers) [22]; and (b) cross-sectional view of a conical one (typical for hold frames in bulk carriers) [23]

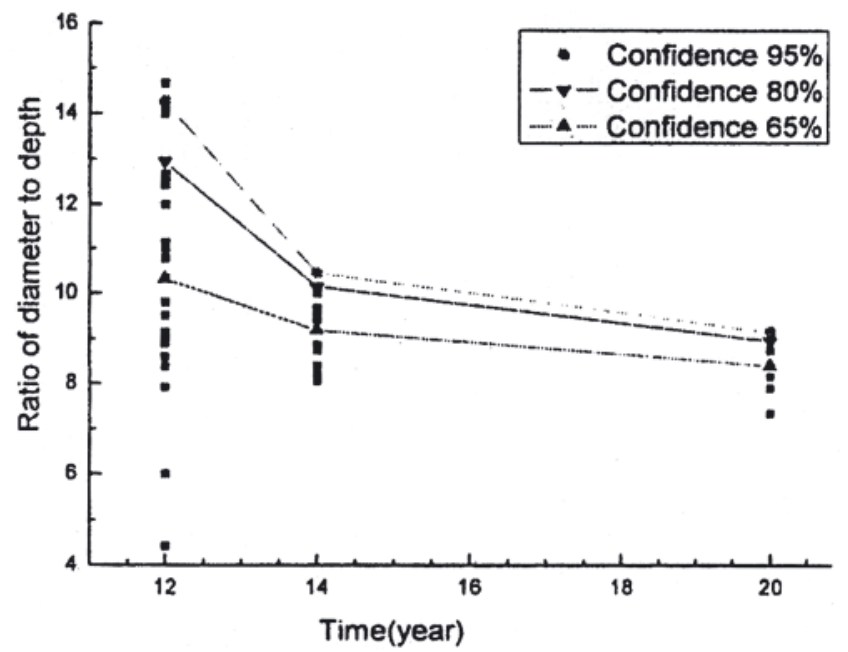

Fig. 6. Pit's shape and its evolution on different ships (diameter-to-depth ratio is an inverse of the aspect ratio) [24]

considered not generated at sulphides and spherical ones. It is considered that mechanical damage to the coatings occurs at very small points due to scratches by cargoes, then the corrosion process starts locally at these points, that leads to the formation of corrosion pits. As the number of the pits increases, the pits can coalesce and overlap. They are initiated exactly on surface of steel, therefore they exhibit lower aspect ratios (depth-todiameter ratio equal to $0.1 \div 0.125)$ than spherical pits $(0.167$ $\div 0.25$ ) originated inside material within "caverns" placed at dissolute sulphide inclusions (Fig. 6a). In earlier stages of exposure the aspect ratio is often lower than 0.1 (Fig. 6b). This is evident that in 20-year old bulk carriers pits (as measured) are smaller than in 14-year old ones. This is presumably a result of general corrosion progress and overlapping of individual pits.

\subsection{Grooving corrosion}

Grooving corrosion is a form of pitting corrosion with joined pits. This form of corrosion is usually observed along 
welds, and heat affected zones (HAZ) are attacked most intensively. Cross section of fillet welded joints with grooving corrosion, general corrosion and a transitional form of corrosion are compared in Fig. 7a, 7c and 7b, respectively. The main reason presumably is electrochemical potential of the heat affected zone which is less noble than parent material and weld metal. A relative potential difference of about $100 \mathrm{mV}$ between HAZ and the central part of the weld has been reported [25]. An additional reason can be dust and dirt accumulated at the region of the toe of weld. Yuasa and Watanabe [25] have fairly stated that, in practice, the cause of this corrosion is generally defective painting. Grooving corrosion can be prevented by satisfactory painting. However, during repair work, the quality of the painting work is generally poor, that leads to the problem in question.

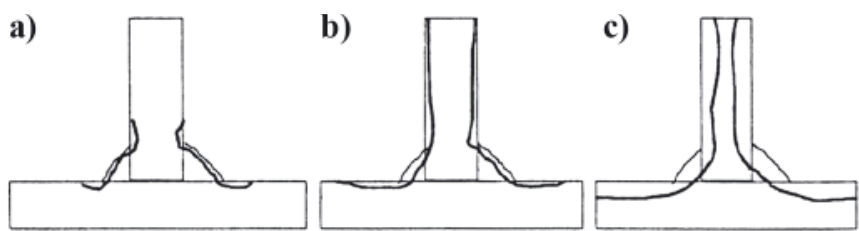

Fig. 7. Cross sectional view of corroded fillet welded joints of frames of bulk carriers: (a) 12 -year old, and (b) 14-year old; and a 22-year old tanker bottom plate: (c) [26]

\section{RELATION BETWEEN MICROSTRUCTURE AND PITTING SUSCEPTIBILITY}

In steels with martensite-ferrite structure pits are predominantly initiated in the ferrite bands [27]. In steels with martensite-pearlite structure pits are preferentially initiated on martensite [27]. In a pearlitic-ferritic steel commonly applied to ship and offshore structures, tested in salt water, pits were initiated earlier and grew faster in pearlite then in ferrite [28]. As pits start growing in one phase they will give cathodic protection to growing pits in the other phase and therefore deactivate the growing process [5]. Miller and Akid [29] reported that some micro-structural barriers (such as grain boundary) can influence the pit growth rate - the rate drops when the pit approaches the barrier.

A new bainite-ferrite steel for application in shipbuilding industry has been developed in Japan [30]. The new steel with bainite-ferrite microstructure exhibited longer corrosion fatigue crack initiation life as compared to conventional ferrite-pearlite steels. This extended crack initiation life in the ferrite-bainite steel has been attributed [30] to small number of corrosion pits which are potential sites of initiation of corrosion fatigue cracks. The small number of the pits might be caused by high homogeneity of ferrite-bainite steel to general corrosion which is slower than for ferrite-pearlite steel. General corrosion of ferritebainite steel is uniform and evidently slower than for ferritepearlite steels because of fine and homogenous microstructure. The ferrite-pearlite microstructure is not so homogeneous, therefore in this case general corrosion is non-uniform.

\section{STATISTICAL DISTRIBUTION OF CORROSION PIT DEPTHS}

Modelling of pitting-induced corrosion fatigue process requires to know statistical distribution of the pit depths since the distribution of corrosion pits have a substantial effect on the distribution of fatigue life [31]

Melchers [20] analysed the uncertainty (or scatter) in the data concerning pit depth at any given point of time. For pit growth under aerobic conditions (i.e. in the phases 1 and 2 of the model shown in Fig. 3), pit depth distribution, at least for deeper pits, approximately satisfies the normal distribution. For anaerobic conditions (the phases 3 and 4), both supply rate of nutrient and proportion of surface covered by pits, with no knowledge of the probability density of each, may be represented by a unimodal distribution as the normal distribution. Thus the individual pit depth will be distributed in compliance with Cauchy distribution. Then the extreme pit depths are asymptotically distributed in compliance with Fretchet distribution. However, if the density of pitting is relatively well described with little uncertainty, the underlying pit depth distribution is approximately normal and hence the asymptotic extreme value model is of a Gumbel type.

Not only distribution of pit depths seems to be important, but also a rigorous probabilistic analysis to quantify the probability of the crack initiation at pits of different sizes, would be useful [32].

\section{CONCLUSIONS}

1. Pitting corrosion in steels is almost always initiated at sulphide inclusions (90\% MnS, remaining mainly $\mathrm{FeS}$ ), which are cathodic, but their surfaces and the surface of surrounding steel are contaminated with sulphur, therefore they are more anodic than matrix far from inclusion.

2. Grooving corrosion takes place in HAZ close to toe of weld due to electrochemical potential difference between separate zones of welded joints.

3. Protective coatings like paints successfully prevent general corrosion during a relatively long period but they enhance tendency for local corrosion like pitting corrosion and grooving corrosion to be initiated in sites of inherent defects of coating (blisters or pores) or in-service - generated defects (pop -offs, scratches, etc).

4. In ferrite-pearlite steels, pearlite is more liable to suffer corrosion pitting. Therefore the greater carbon content the greater pearlite content, and the higher pitting corrosion susceptibility of steel could be probably expected. Melchers [8] is of opposite opinion. Corrosion of a new ferrite-bainite steel for shipbuilding industry is almost uniform with much smaller number of pits compared to conventional ferritepearlite steels because of much fine and much homogeneous microstructure of the ferrite-bainite steels compared to conventional steels.

5. Oxygen access to the initiated pit is restricted by its shape and a rust blister covering the pit, therefore an oxygen concentration cell which facilitates the pit growth, exists. Many authors reported evident drop of electrochemical potential within the pit, where iron is dissolved anodically as $\mathrm{Fe}^{2+}$ ions which diffuse outwards, whereas chloride anions migrate into the pit. On their way outwards, anions $\mathrm{Fe}^{2+}$ are partly hydrolysed with the acidification of electrolyte within the pit. This acidification and a higher concentration of $\mathrm{Cl}^{-}$within the pit accelerates the pit growth rate too.

6. Biological activity of sea water can play an important role in pitting corrosion in case of both short-term exposure (measured in days and months) and long-term exposure (measured in years). Anaerobic conditions built up even after short-term exposure at the bottom of fuel and oil tanks but after a long-term exposure of structures working in seawater, are propitious for sulphate-reducing bacteria (SRB), that markedly enhance the pit growth rates. 


\section{Acknowledgements}

This work has been performed in the scope of the project RISPECT ("Risk-Based Expert System for Through-Life Ship Structural Inspection and Maintenance and New-Built Ship Structural Design") which has been financed by the UE under the contract SCP7-GA-2008-218499.

\section{BIBLIOGRAPHY}

1. Domański A., Birn J.: Corrosion of ships and their prevention (in Polish). Wydawnictwo Morskie, Gdańsk, 1970,

2. Melchers R.E.: Development of new applied models for steel corrosion in marine applications including shipping. SAOS, 2008, Vol.3, No.2, pp.135-144.

3. Shi P., Mahadevan S.: Probabilistic corrosion fatigue life prediction. $8^{\text {th }}$ ASCE Specialty Conference: Probabilistic Mechanics and Structural Reliability. 2000

4. Zhang R., Mahadevan S.: Reliability based reassessment of corrosion fatigue life. Structural Safety, 2001, Vol.23, pp.77-91.

5. Butler G., Stretton P., Beynon J.G.: Initiation and growth of pits on high purity iron and its alloys with chromium and copper in neutral chloride solution. British Corrosion Journal, 1972, Vol.7. July, pp. 168-173.

6. Wang Q.Y., Kawagoishi N., Chen Q.: Effect of pitting corrosion on very high cycle fatigue behaviour. Scripta Materialia 2003, Vol.49, pp.711-716.

7. Wranglen G.: Pitting and sulphide inclusions in steel. Corrosion Science, 1974, Vol.14, pp.319-349.

8. Melchers R.E.: Pitting corrosion of mild steel in marine immersion environment - Part 1: Maximum pit depth. Corrosion, 2004, Vol.60, No. 9, pp.824-836.

9. Melchers R.E.: Pitting corrosion under marine anaerobic conditions - Part 1: Experimental observations. 2006, Vol.62, No. 11, pp.981-988.

10.Akid R., Dmytrakh I.M., Gonzales-Sanchez J.: Fatigue damage accumulation: the role of corrosion on the early stages of crack development. Corrosion Engineering, Science and Technology, 2006, Vol.41, No.4, pp.328-335.

11.Nakai T., Matsushita H., Yamamoto N., Arai H.: Effect of pitting corrosion on local strength of hull structural members. Class NK Technical Bulletin, 2005, pp.29-49.

12.Ishihara S., Saka S., Nan Z.Y., Goshima T., Sunada S.: Prediction of corrosion fatigue lives of aluminium alloy on the basis of corrosion pit growth law. Fatigue \& Fracture of Engineering Materials \& Structures, 2006, Vol.29, pp.472-480.

13. Novokshchenov V.: Brittle fracture of prestressed bridge steel exposed to chloride-bearing environment by corrosiongenerated hydrogen. Corrosion, 1994, Vol.50, No.6, pp.477-484.

14.Biezma M.V., Rio-Cologne B.: Influence of various marine conditions on corrosion behaviour of AISI C1118 steel. Inżynieria Materiałowa (Material Engineering), 2001, Vol. 22, No.4, pp.227-230.

15.Linder J., Blom R.: Development of a method for corrosion fatigue life prediction of structurally loaded bearing steel. Corrosion, 2001, Vol. 57, No.5, pp.404-412.

16.Kumakura Y., Takanashi M., Fuji A., Kitagawa M., Ojima M., Kobayashi Y.: Fatigue strength of coated steel plate in seawater. Proc. Ninth Int. Offshore and Polar Engineering Conference, Brest, France, May 30 - June 4, 1999, Vol.4, pp. 108-113.

17.Kawai S., Kasai K.: Considerations of allowable stress of corrosion fatigue (focused on the influence of pitting). Fatigue \& Fracture of Engineering Materials \& Structures, 1985, Vol.8, pp.115-127.
18.Wang Y., Wang Y., Huang X. Cui W.: A simplified maximum pit depth model of mild and low alloy steels in marine immersion environment. Journal of Ship Mechanics, 2008, Vol.6, No.1, pp.401-417.

19.Kobzaruk K.A.V., Marichev V.A.: Corrosion and corrosion fatigue resistance of steels in real marine environment and in laboratory (in Russian). Physical Chemical Mechanics of Materials,1981, Vol.16, No 2, pp.15-21.

20.Melchers R.E.: Pitting corrosion under marine anaerobic conditions - Part 2: Statistical representation of maximum pit depth, 2006, Vol.62, No 12, pp.1074-1081.

21.Salvarezza R.C., Videla H.A.: Passivity breakdown of mild steel in seawater in the presence of sulphate reducing bacteria. Corrosion, 1980, Vol.36, No.10, pp.550-554.

22.Matoba M., Yamamoto N., Watanabe T., Umino M.: Effect of corrosion and its protection on hull strength ( $1^{\text {st }}$ report) (in Japanese). J. Society of the Naval Architects of Japan, 1994, Vol.175, pp.271-280.

23.Nakai T., Matsushita H., Yamamoto N.: Effect of pitting corrosion on the ultimate strength of steel plates subjected to in-plane compression and bending. J. Marine Science and Technology, 2006, pp.52-64.

24.Wang Y, Wu X., Zhang Y., Huang X., Cui W.: Pitting corrosion model of mild and low-alloy steel in marine environment - Part 2: The shape of corrosion pit (in Chinese). Journal of Ship Mechanics, 2007, Vol.11, No.5.

25. Yuasa M, Watanabe T.: Fatigue strength of corroded weld joints. Class NK Technical Bulletin, 1996, Vol.14, pp.51-61.

26.Matsushita H., Nakai T., Yamamoto N.: A study on static strength of corroded fillet welded joints for ship structures (in Japanese). J. Society of the Naval Architects of Japan, 2004, Vol. 195, pp.291-297.

27.Cui N., Qiao L.J., Luo J.L., Chiovelli S.: Pitting of carbon steel with banded microstructures in chloride solutions. British Corrosion Journal, 2000, Vol.35.

28. Boukerrou A., Cottis R.A.: Crack initiation in the corrosion fatigue of structural steels in salt solutions. Corrosion Science, 1993, Vol.35, pp.577-585.

29.Miller K.J., Akid R.: The application of microstructural Fracture Mechanics to various metal surface states. Proc. Royal Society A ?, 1996, Vol. 452, pp. 1411-1432.

30.Konda N., Suzuki S., Tada N., Kho Y., Kazushige A., Watanabe E., Yamamoto M and Yaima H.: Effect of microstructure on fatigue properties of steel in seawater-development of steels for high resistance to fatigue in ships, Part 2. J. Soc. Naval Architects of Japan, 2001, Vol.191, pp.229-237.

31.Dolley E.J., Lee B., Wei R.P.: The effect of pitting corrosion on fatigue life. Fatigue \& Fracture of Engineering Materials \& Structures, 2000, Vol.23, pp.555-560.

32.Sankaran K.K., Perez R., Jata K.V.: Effect of pitting corrosion on the fatigue behaviour of aluminium alloy 7075-T6: Modelling and experimental studies. Materials Science and Engineering, 2001, Vol. A 297, pp223-229.

\author{
CONTACT WITH THE AUTHOR \\ Marek Jakubowski, Assoc. Prof. \\ Faculty of Ocean Engineering \\ and Ship Technology \\ Gdansk University of Technology \\ Narutowicza 11/12 \\ 80-233 Gdansk, POLAND \\ e-mail: marjak@pg.gda.pl
}

